\title{
Correction to: Dynamic Data Driven Applications Systems
}

Frederica Darema (D), Erik Blasch (D), Sai Ravela (D), and Alex Aved (D)

\section{Correction to: \\ F. Darema et al. (Eds.): Dynamic Data Driven Application Systems, LNCS 12312, https://doi.org/10.1007/978-3-030-61725-7}

The book was inadvertently published with a typo in the main title on the cover and in the frontmatter as "Dynamic Data Driven Application Systems" whereas it should be "Dynamic Data Driven Applications Systems". The main title has been corrected in the book. 